\title{
The Effect of Using Mobiles in Students' Ability in Translation from English into Arabic at Jadara University in Jordan
}

\author{
Mohammad AlShehab \\ The Department of English Language and Literature, Jadara University, Irbid, Jordan \\ Email address: \\ Jordan_1948@yahoo.com \\ To cite this article: \\ Mohammad AlShehab. The Effect of Using Mobiles in Students' Ability in Translation from English into Arabic at Jadara University in \\ Jordan. International Journal of Applied Linguistics and Translation. Vol. 3, No. 3, 2017, pp. 32-39. doi: 10.11648/j.ijalt.20170303.11
}

Received: April 19, 2017; Accepted: May 8, 2017; Published: May 29, 2017

\begin{abstract}
The current study aims at touching upon the effect of mobile method on improving students' translation from English into Arabic. The sample of the students was chosen randomly from the English Department at Jadara University in Jordan. The sample consisted of 40 translation students. It was divided into two similar Groups, Experimental, and Control. Experimental students were asked to use their mobiles in translation, while the Control students used a normal method in translating English or Arabic vocabularies into their equivalents. T-test for independent samples' was used to compare between the two Groups at pre and post tests. The results revealed the higher level in translation for the benefit of the Experimental Group. It also revealed statistical differences between pre and post tests for the Experimental Group. Recommendations and suitable suggestions were set up for future research.
\end{abstract}

Keywords: Translation, Jadara University, Students' Ability, Mobile Method

\section{Introduction}

The popularization of the computer and its technology had led very quickly to use it for translation. It is used through the appearance of useful translator tools including translation memories, the translation management programs, electronic corpora, and so forth (Matusov et al. 2006). They continue that the breakthrough happening in the computer technologies may lead to new theories in translation to be more functional than paper and pen translation. In other words, E-learning such as Machine translation (MT) and Computer-Assisted Translation (CAT) are intended to replace translators. Software in MT aims at assembling all the information necessary for translation in one program so that a text can be translated. Sim et al (2007), on the other hand, indicate that the sector of communities stimulated the demand for electronic translation leading to the development in countries such as France, Germany, Canada and Japan of new translation systems from one language to another. With global interconnectivity, modern day activities are fuelling the growth of the translation because CAT responds more realistically to translation and supporting actual needs since it has a human touch. Chhabra (2012) emphasizes the use of eLearning devices in teaching English, like Internet, YouTube, Skype, Twitter, and Mobile. He indicates that these devices give enormous opportunities in practicing language skills in a foreign language class/individual with classes/ individuals in other countries. Al shehab (2013) indicates that UNESCO has recommended using mobile technologies in educational systems to support teachers' and students' development. UNESCO policy ensures the utilization of mobile device, where possible, in educational resources, curricula, and plans. By using the mobile devices, students and teachers can get more benefit as they own this device more than any other technological device.

Nowadays it seems that mobile phones are used by everyone at home, school and anywhere. Thus, we ought to know how mobile phones technology can support learning in the second language classroom. The ever-increasing functions invented in mobile inspire most students to use it. For the importance of this subject, a number of researchers describe some practical ways to support second language learning by using mobile, both inside and outside the classroom. Chinnery (2006) says that recent interest in the 
potential for mobile phones to support learning and teaching has been driven by the fact that mobile phones are relatively cheap powerful. Similarly, Kukulska-Hulme and Traxler (2005) point out that learners are used to working with mobiles more than computers, they used mobiles for many activities, from reading articles to emailing.

Ferry, (2009) states that mobile phones are becoming popular as many people can afford them. In education, mobile phones have led to the evolution of new paradigm known as mobile learning. Currently, UNESCO (2012), the use of mobile communication devices has gone beyond the traditional communication role, it is now used in supporting teaching and learning. The rapid growth of access to mobile phones around the world, particularly in Africa and the Middle East regions have a potential of improving teaching and learning to enable national education system transformation. Huang et al (2010) says that mobile learning applications can facilitate students teaching and learning. By this way, they can interact with others collaboratively anytime and anywhere. They continue that modern mobile phones can be used to help students to access web based contents, share it, collaborate with others and create media rich deliverable for the classroom teachers as well as global audience. Similarly, the universities in the United Kingdom (UK), Ferry(2009) says, have made the use of mobile phones to store and retrieve information such as e-books, instructional materials, reviewing students' marks. For instance, teachers in higher education in UK have made use of SMS as prompt for course requirements, polling classes, pop quizzes to students and sending information about time table and reminding students about dates for examination.

\section{Mobile Features}

Mobiles have many features that are being utilized for various educational practices. The use of Short Message Services (SMS), GPS, camera, browsing, downloading, bluetooth, Wi-Fi, voice calls, and gaming makes it more effective (Kizito, 2012 \&Hoppe 2009). They say that SMS System can be used to help students learn foreign languages, and teachers can 'use SMS to communicate with one student or even one group of students. Hoppe (2009) and Ferry (2009) meet each other in saying that students can use browsers to check emails, read materials such as eBooks, and watch lecture from anywhere and at any time. Browsing with cell phones is one convenient way for students to surf online. Most of the modern mobile phones are incorporated with browsing applications such as Opera Mini, Internet explorer, Mozilla fire fox, Opera and Google chrome. Kafyulilo (2012) indicates that mobile phones have downloading feature which can be used by students and tutors to download various kinds of materials through their mobile phones easily. Teachers can download video through their mobile phones and present them to students through a TV set available in the classrooms. Mobile phones can be used for sharing information resources through Infrared, Bluetooth and Wi-Fi. Other applications including emails, Google drive, and social media can equally be used for sharing academic information resources. According to Common Wealth of learning (2008), teachers can share with students' movies, audio files and other learning materials through their mobile phones. Most of the mobile phones have features which can be used for recording and playing multimedia contents. Students can greatly benefit from having a camera on the cell phones for documenting visual materials and collecting scientific data.

\section{Mobile Phones in Language Classrooms}

Using mobile phones in the second language learning generally focuses on developing the four skills (integrating speaking with listening and reading with writing) (Reinders and Lewis 2009), such as the following:

a) Using the Notes feature to collect everyday language. Most mobile phones have a feature that allows them to take notes. Students can use this feature to take notes on English they read or hear outside school and either present the notes to the class or send them to others as a text message.

b) Using the Camera to take pictures of text is one of the easiest ways to use a mobile phone. Students can take pictures of English texts by using the Camera on their mobile phones. If students do not have a data connection, they can transfer pictures to a computer and upload them from there.

c) Using the Voice Memo Recorder feature to record conversations outside the classroom. Students can record interviews or conversations they engage in outside the classroom. Students can play the interviews and conversations in class for feedback and discussion.

d) 5Using the Text Messaging feature for writing is a feature that should be encouraged to improve students' writing as it is associated by fun far away from boring assignments. If students are not ready to write essays, they can practice with shorter texts to develop their writing skills. Students can create a story together by contributing one text message at a time. Each student writes a sentence or two and then sends this on to the next student who adds another message, and so on until the story is completed.

e) Using the mobile phone to keep a blog. This requires a phone with a connection to the Internet (or the use of a wireless network at home or perhaps at school). Students use the Text Messaging and Camera features to add messages and post pictures to their personal blogs. This is great for writing about personal experiences, places visited, and people met, but it can also be used as an activity in which students collect information and report it like journalists. Teachers can read these blogs and provide feedback, request more information, or ask students to comment on each other's work.

A study done by Thornton and Houser (2003) shows that a Short Message Service (SMS) text messages can be used to send out vocabulary items at spaced intervals, thus increasing student retention. For example, you could text the words covered in class to encourage students to review them outside the school context. By sending out the words multiple times, you increase the chances that students will remember them. They report that young Japanese learners prefer to use mobile 
phones for many activities, from emailing to reading books. Chen, et. al (2008) have done a research on the use of mobile phones for the delivery of vocabulary materials to English learners in Taiwan. It shows that students enjoy using their phones because of the easy access to materials and the ability to practice anytime and anywhere.

Baleghizadeh and Oladrostam (2010) have done a study to improve the grammatical knowledge of EFL students through using mobile phones. Forty pre-intermediate Iranian female students participated in this study. The subjects in both EG and $\mathrm{CG}$ were provided with an opportunity to review and recycle six grammatical forms: present perfect versus simple past, direct versus indirect questions, and comparatives versus superlatives. During class discussions designed in such a way as to elicit the given grammatical items, the subjects in the EG recorded their voice on their mobile phones and as an out-of-class assignment analyzed their spoken mistakes and commented on them in the subsequent session. The subjects in the CG, however, received no extra treatment at all. The results showed the high level for EG that had benefited from mobile device than the subjects in the CG. The study done by UNESCO, (2012) has shown that mobile learning projects in South Africa have been used to improve teaching system especially teaching biology subjects. Furthermore, the study conducted by Utulu (2012) in Nigeria revealed that mobiles phones were used by students for communicating with the lecturer in charge of the course collecting data, and sending emails to lecturers and share knowledge.

A study was conducted by Hashemi and Abbasi (2013) on 180 third-grade high school students to investigate whether using mobile phones had an effect on the learners' vocabulary retention. The results of the study proved that using mobile phones was helpful to EFL learners in terms of vocabulary retention. The findings of the study also revealed that a greater attention to the features of a new word and its text environment will facilitate its memorization.

In Jordan, Al Shehab (2013) indicates that the use of the Internet in Jordan has extremely grown. It has been used at most universities and organizations in Jordan. Students normally use the Internet in schools and universities. Socially, students can use the Internet for chatting with their colleagues, relatives, and friends all over the world. Using facebook and Yahoo Messenger may enable them to achieve more entertainment. AlShehab adds that technological methods are needed for teaching and learning languages. Students can improve their spelling, writing, and obtaining more synonyms. Accordingly, by obtaining more English vocabularies, students' translation could be enhanced.

\subsection{Research Problem}

A number of studies in Jordan in the realm of e-Learning impact on language skills had been written, e.g., Jafar (2008), ignores its effect on students' translation. Only a few number of studies tackled translation such as the study of AlShehab (2013) that has revealed the effect of e-Learning in improving students' translation. The study showed that students who used e-learning achieved the best. Therefore, The researcher has vowed to hold similar studies using various technological tools, as no sufficient attention has been paid to this subject. He decided to delve into this rare subject to get rid of weakness in students' translation. Consequently, mobile devices, as one of these tools, is an important issue to be studied, and the gap of such research will be bridged.

\subsection{Research Objectives}

The study aims at examining the students' ability in translation, and to study the differences between the two groups by analyzing the impact of using the mobile devices in teaching translation at Jadara University in Jordan.

\subsection{Research Questions}

The following research questions are investigated to achieve its previous objectives:

Q1. To what extent could a Mobile device improve the ability of students' translation at Jadara University in Jordan?

Q2. Are there any significant differences between the mean scores of the two Groups in posttests?

Q3. Are there any significant differences between the mean scores of EG in pre and posttests?

\subsection{Limitations of the Study}

The study is limited to a technical test with its three related questions. It is also limited to a sample of 40 students chosen from the English Department at Jadara University. In this regard, the results may not be generalized to other universities in Jordan.

\subsection{Significance of the Study}

The current study is the first attempt to examine the students' ability in translation dealing with a Mobile device at the national level. This research is expected to give a significant background about the capacity of e-Learning devices in students' ability. This study is also very important for scholars, educators, and decision makers, because the problem it deals with is persistent and crucial. It will benefit postgraduates and scholars in carrying out comparable research and studies. It is hoped that the results of this study may add to those who have future vision for teaching and learning. It is a helpful step to prepare a corrective teaching method for translation.

\section{Methodology}

\subsection{The Participants}

The study involved a sample of 40 Jordanian translation students with about 20 percent. A simple random procedure was employed in selecting the sample out of (200) students. They were in the fourth year; they were enrolled in the second semester of the academic year (2015-2016) at Jadara University in Jordan. The subjects had studied different 
courses in translation from English into Arabic and vice versa. They passed a pre request test to measure their proficiency when they joined the university. Therefore, all of them are similar in their educational background. The sample is divided into two Groups, the Experimental Group (EG) and the Control Group (CG) with 20 students for each group. The first Group (EG) was taught by the mobile method for one semester. The second Group (CG) was taught by talk and chalk method for one semester, too.

\subsection{The Procedures of the Study}

The researcher follows the procedure done by AlShehab (2013) in e-Learning. The EG had been given a general translation course as an online course. The course was divided into two phases. In the first phase, the researcher dealt with words and expressions for ten lectures within the semester. The students were asked to find out synonyms for English expressions by using mobile applications such as WhatsApp and Messenger, followed by translating them into Arabic. The students have to collect and write down these words in a small booklet.

In the second phase, the researcher tackled with translation on the level of sentences for the rest of lectures. The students were divided into heterogeneous groups, and had been given a number of technical sentences ranged from shorter to longer. The students were informed to translate the sentences into Arabic by sending text messages among themselves within their group. Therefore, fun can be created inside the classroom. Their translation had been discussed in pairs and groups followed by collective and self-assessment. Finally, the last versions had been exposed to their instructor to be corrected. The instructor's role now is to discuss their mistakes in translation. Their work was evaluated by giving the right translation. The students on their role collected and compiled the evaluated sentences in their booklets or profiles. By doing this, students can learn how to express their thoughts and ideas in simple language. As a result, a small handbook or student's booklet was set up. On the other hand, CG students were taught by chalk and talk as a traditional method for teaching translation.

\subsection{Data Collection}

For collecting data, pre and post tests were used to verify the students' ability. The pretest was used at the beginning of the semester. The test included a technical text about the mobile. Three questions were stemmed from the text as in 'Appendix A' (p.17). The first question was about translating the underlined expressions and terms for 20 marks. The second question was about translating the four long sentences from the text for 50 marks. The third question was about extracting five verbs, five nouns, and five adjectives from the text and giving their suitable Arabic equivalences for 30 marks.

To ensure the validity of the test, it was given for a panel of judges at Jadara University in Jordan to set their comments and views in details. Their comments were taken into consideration, followed by approving the final version and its suitability for testing students. For more validity of the text, the researcher adopted the committee translation. The English text was given also for two instructors in the Department of Translation at Jadara University in Jordan. They were asked to translate it. Their translation was compared and the last version, as in 'Appendix B' (P. 18).

For achieving the test' reliability, the method of test-retest was used at the beginning of the semester. The test was administered for five translation students outside the sample at Jadara University in Jordan. After a month, the test was readministered to the same students. The reliability coefficient was computed by using Pearson Correlation Coefficient. It was 0.95 . A parallel test was used later at the end of the semester to check their progress. The following criterion for evaluating students' translation was adopted:

Table 1. The Criteria of Translating or Evaluating English Test into Arabic.

\begin{tabular}{llllll}
\hline \multirow{2}{*}{ Question/N. of items } & $\begin{array}{l}\text { Instructor } \\
\text { Translation }\end{array}$ & \multicolumn{4}{l}{ Student translation } \\
\cline { 2 - 6 } & Excellent & V. G & Good & Fair & Poor \\
\hline $1^{\text {st }}(10 \times 2.5)$ & 25 & 20 & 18 & 13 & 0 \\
$2^{\text {nd }}(3 \times 15)$ & 45 & 40 & 35 & 25 & 0 \\
$3^{\text {rd }}(30 \times 1)$ & 30 & 24 & 21 & 15 & 0 \\
\hline
\end{tabular}

Regarding the first and the third questions, students should give the exact meaning or the correct synonyms with $(2.5,1.25)$ marks respectively. It is obvious from table (1) that when the student's translation is similar to that of the instructor's, the items in the first question score $(2.5 \times 10=25)$, afterward the level is excellent. Concerning the third question, there has been (1) mark for each item, thus the items and their equivalences have scored $(1 \times 30=30)$ marks. When, in the second question, the student's translation is similar to that of the instructor's, each sentence (a, b, and c) scores 15, which means that the student has achieved an excellent level. When the student gives the general meaning, it means that he has achieved above 40 with a v.good level. Whereas, when the meaning is approximately given, the level is evaluated as "good" and the sentences scores around 35. If the translation of the sentence is only partially right, it will be graded as 25 and its level is "fair." Finally, the sentence may be given a zero score, which is completely wrong and has a "poor" level. Here, the researcher is unable to discuss the committed errors in translation. He dealt only with the mean scores at pre and posttests. So, the impact of the mobile method in translation and its role in improving ability will be recognized.

\subsection{Data Analysis}

The responses were collected and corrected. The researcher used statistical methods for quantitative data to demonstrate students' ability in translation. They were used to compute mean scores and percentages of the students' responses from data collected through tests. T-test was also used to compare between the mean scores of posttest of the two Groups. On the other hand, some responses were analyzed qualitatively. 


\subsection{Variables}

This study dealt with the following variables:

a) Independent variable: using mobiles in translation.

b) Dependent variable: students' ability in translation.

\section{Results and Discussion}

To answer the first question of this study: To what extent could a mobile device improve the ability of students' translation at Jadara University in Jordan?

Table 2 shows the mean scores and percentages that are computed for the two groups at pre and posttests. At pre test the mean score for the EG is 59.95 percent, while the mean score for the $\mathrm{CG}$ is 59.3 percent.

According the posttest, the mean scores are computed and tabulated also in table 2. It exposes the mean scores of 80.75 percent for EG, while the CG obtains the mean score of 60.55 percent. It has been shown that the EG has achieved the highest, while the less level is registered for the CG.

The range of score for the EG, it is from 95 percent to 65.0 percent for EG. There are 19 students who scored above 70 percent. The range of scores for CG is from 75.0 percent to 42.5 percent. Two students only have obtained above 70 percent with a good level, while one student failed in getting the pass score which is 50 percent. The EG has obtained nearly a v.good level. An improvement in their mean scores has been noticed. It is a high level in comparison with 59.95 percent in pre-test. This study meets the one of Baleghizadeh and Oladrostam (2010), they use mobile device to improve the grammatical knowledge. The two studies show a high level for the benefit of EG. This signifies to the comfortable reading text on small screens, as this multimedia captures their interest, and help them in acquiring new vocabularies. Finally, the impact of mobile phones in students' daily lives is more dominant than any other electronic device. All the students whom I taught appreciated the importance of mobile device in translation. Therefore, they showed extremely good results, and what impressed me most about my students was their immersing in mobile translation lectures.

Table 2. Pretest and Posttest Results for the Two Groups.

\begin{tabular}{lllll}
\hline Test & Pretest & \multicolumn{3}{c}{ Posttest \% } \\
\hline no & CG & EG & CG & EG \\
1 & 55 & 60 & 75.0 & 95.0 \\
2 & 60 & 55 & 72.5 & 90.0 \\
3 & 62 & 62 & 65.0 & 87.5 \\
4 & 50 & 45 & 62.5 & 87.5 \\
5 & 60 & 70 & 62.5 & 85.0 \\
6 & 50 & 48 & 56.0 & 80.0 \\
7 & 45 & 55 & 62.5 & 75.0 \\
8 & 56 & 66 & 60.0 & 82.5 \\
9 & 70 & 70 & 57.5 & 82.5 \\
10 & 40 & 30 & 60.0 & 80.0 \\
11 & 70 & 77 & 57.5 & 80.0 \\
12 & 55 & 50 & 55.0 & 85.0 \\
13 & 60 & 60 & 55.0 & 72.5 \\
14 & 50 & 55 & 65.0 & 77.5 \\
\hline
\end{tabular}

\begin{tabular}{lllll}
\hline Test & Pretest & \multicolumn{3}{c}{ Posttest \% } \\
\hline 15 & 66 & 70 & 42.5 & 77.5 \\
16 & 54 & 60 & 50.0 & 77.5 \\
17 & 70 & 66 & 67.5 & 75.0 \\
18 & 67 & 70 & 55.0 & 65.0 \\
19 & 70 & 65 & 65.0 & 82.5 \\
20 & 76 & 65 & 65.0 & 77.5 \\
Mean & 59.3 & 59.95 & 60.55 & 80.75 \\
St.D & 9.6 & 10.9 & 6.7 & 7.5 \\
\hline
\end{tabular}

To answer the second question of this study: Are there any significant differences between the mean scores of the two Groups in posttest?

T-test is used also to compare between the mean scores of the two Groups. Table 3 shows the computed t is 8.9 , while the critical $t$ is 2.042 . Hence, there are statistical differences between the two Groups for the benefit of the Experimental Group.

Table 3. T- Test for Experimental and Control Groups at Posttest.

\begin{tabular}{llllllll}
\hline Group & n & Mean \% & St.D & df & t & Std.err & Sig \\
\hline EG & 20 & 80.75 & 7.5 & \multirow{2}{*}{38} & \multirow{2}{*}{8.9} & 1.30 & \multirow{2}{*}{0.05} \\
CG & 20 & 60.55 & 6.7 & & & 1.48 & \\
\hline
\end{tabular}

It is believed that the differences between Groups may be ascribed to the technological devices and styles that were used in teaching translation for the EG. Students in the EG were taught from the beginning to use the mobile device with the constructivist strategies. These methods are new and attractive in enabling students to be more practical and active. However, they think that receiving information via mobile phones is an important potential use, and can accelerate students' English language learning abilities. The students in the EG were interested in pairs and groups work in translating the given terms, sentences or texts. The highest score for EG reflects the advantages of using mobile phones in the translation process. CG students, on the other hand, were unable to do this, and seem to use the same strategy they had used from the first stage. They were not practiced in using different strategies during their lectures within the semester.

In table 2, the findings indicate the same level of EG and CG. There are no noticeable differences in the performance of the two Groups. This result may be ascribed to their level in the previous academic years. The low level of both groups may be ascribed to the difficulty of translation between English and Arabic languages, as each language has its grammar rules.

To answer the third question of this study: Are there any significant differences between the mean scores of the EG in pre and posttest?

For answering this question, t-test is used to compare between the two mean scores of students in translation regarding the EG at pre and posttests. Table 5 shows the result of $\mathrm{t}$-test. The computed $\mathrm{t}$-for comparing between the two tests for EG- is 7.02, while the critical t is 2.04. As a result, there are statistical differences between pre and post tests for the benefit of posttest. 
Table 4. T-Test for Comparing Between Pre and Posttests for EG.

\begin{tabular}{lllllllll}
\hline Group & Test & n & Mean \% & St.D & df & t & Std.error & Sig \\
\hline \multirow{2}{*}{ EG } & pre & 20 & 80.75 & 7.5 & \multirow{2}{*}{38} & \multirow{2}{*}{7.02} & 1.90 & 0.05 \\
& post & 20 & 59.95 & 10.9 & & & 1.30 & \\
\hline
\end{tabular}

Accordingly, there are differences between the students who were taught by the technological devices and those who were not undergone. Yet they are able to reach the same level of the EG if they have undergone the mobile device process. Moreover, if the $\mathrm{CG}$ is manipulated as the EG, the students will achieve an equivalent level. This emphasized what was said: "the teacher should not teach what he was taught." To enhance students' ability and to stimulate their active participation, the instructor has to use a variety of methods in teaching any subject, and to shift from the traditional approach into a more attractive one. Moreover, it is necessary to use the current technological devices in schools and other academic organizations.

The study meets the studies of (Thornton and Houser, 2003; Chen, et. al, 2008; Baleghizadeh and Oladrostam, 2010; Hashemi and Abbasi, 2013). These studies show the effect of the mobile device in attracting students' attention to be immersed in language lessons. This may reflect students' love to the screen size limitations, which makes the amount of content more manageable than any other teaching materials. This study agrees with the study of Baleghizadeh and Oladrostam (2010) in using the same method, the EG and the CG. They have done a study to improve the grammatical knowledge of EFL students through using mobile phones. It strongly agrees with AlShehab (2013) study that investigates the role of elearning devices in enhancing the accuracy of students' translations.

\section{Recommendations and Suggestions}

In the light of the previous results, it is recommended:

a) Using mobile phones within educational materials, as mobile devices can be effective tools for a broad range of educational activities. It provides a productive language practice.

b) Using mobile devices as writing tools for taking notes and short reports, by measuring how rapidly students can write texts by using various mobile interfaces, such as tiny keypads.

c) Expanding the use of mobile devices indoor and outdoor language activities.

The researcher suggests the following:

a) Conducting more researches in translation from English into Arabic and vice versa using online technologies.

b) Studying the mobile impact on translation and on other language skills could motivate and encourage the use of such methods.

c) Writing academic researches measuring students' and lecturers' attitudes towards the feasibility of using mobile devices in teaching languages.

\section{Conclusion}

To sum up, the results showed a positive level for EG, indicating a majority of university students own and frequently use mobiles. The study explained the effect of using mobiles in improving students' translation. It revealed the higher level for the EG than those who were taught by classical methods. Their mean score is nearly v.good. The study revealed no statistical differences between the two Groups at pretest. It revealed statistical differences between the mean scores at the pre and the post tests for the CG and the EG. Additionally, the study revealed differences between the mean scores at the pre and the post tests for the EG for the benefit of posttest. Despite of the limitations in dealing with translation students at JU, the results of this study are meaningful and contributing something to knowledge and research field. By using mobile methods, students' translation will be enhanced, and the academic research will be developed. Consequently, mobile devices can be effective tools for delivering foreign language learning materials to students. These telecommunication technologies have increased the need for having the ability to communicate with other nations either for learning or teaching.

\section{Appendix A}

\section{Students' Test}

Read the following scientific text and answer the questions that follow.

Several types of mobile technologies are available, such as wireless laptop computers, Personal Digital Assistants (PDAs), and electronic dictionaries, although mobile phones are one technology that has started to attract particular attention from educators. One of the primary reasons for the popularity of the mobile phone is the widespread infiltration of the market, particularly in Japan and the US. This means that there is no need for the institution (or in many cases, the teacher) to provide learners with the hardware in order to incorporate a mobile learning component into their teaching context. Added to this is the fact that mobile phones are relatively inexpensive as compared with, for example, wireless laptop computers, and with functions such as Internet browsers that are available in current mobile phones, the range of possibilities of mobile phones as tools for learning increases even further. In contrast, most modern mobile phones have either e-mailer Short Message Service (SMS) functionality, which means that information can be forwarded to and from mobile phones by teachers or students. Internet -capable mobile phones allow immediate connection to a server, which makes it possible for learners to retrieve updated or specific information as they require it, and for teachers to maintain detailed logs of access.

Q1. Translate the underlined English terms into Arabic equivalence. (20 mark)

Q2. Translate these sentences. (45 mark) 
a. One of the primary reasons for the popularity of the mobile phone is the widespread infiltration of the market, particularly in Japan and the US.

b. In contrast, most modern mobile phones have either emailer Short Message Service (SMS) functionality, which means that information can be forwarded to and from mobile phones by teachers or students.

c. This means that there is no need for the institution (or in many cases, the teacher) to provide learners with the hardware in order to incorporate a mobile learning component into their teaching context.

Q3. Fill this table with the suitable English derivatives whenever possible, and write down the Arabic equivalents of all the words. (35 mark)

$\begin{array}{llll}\text { Verb } & \text { Noun } & \text { Adjective } \\ \text { English Arabic } & \text { English Arabic } & \text { English Arabic }\end{array}$

\section{Appendix B}

\section{Arabic Translation of Students' Test}

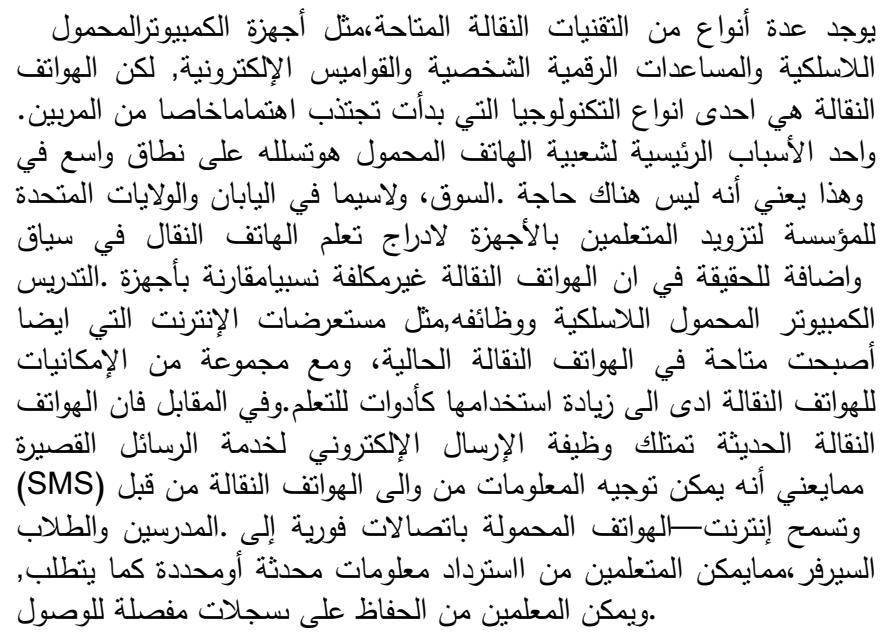

\section{References}

[1] AlShehab, Mohammad. (2013).The Impact of E-Learning in Students' Ability in Translation From English into Arabic at Irbid National University in Jordan. Journal of education and practice, Vol.4, N., 14, pp. 123-133.

[2] Baleghizadeh, S., and Oladrostam, F. (2011). The Effect of Mobile Assisted Language Learning (MALL) on Grammatical Accuracy of EFL Students. Special issue: The Internet and Technology in EFL/ESL, Vol. 34 (2), Shahid Beheshti University, G.C., Tehran, Iran.

[3] Bosch, T. E. (2009). Using online social networking for teaching and learning: Facebook use at the University of Cape Town. Communication, South African Journal for Communication Theory and Research, Vol. 35 (2).

[4] Chen, N., Hsieh, S and Kinshuk. W. (2008). Effects of shortterm memory and content representation type on mobile language learning. Language Learning and Technology 12 (3): 93-113.
[5] Chinnery, G. (2006). Going to the MALL: Mobile assisted language learning. Language Learning and Technology 10 (1): 9-16.

[6] Chhabra, P. (2012): Use of E-Learning tools in teaching English, International Journal of Computing \& Business Research ISSN (Online): 2229-6166. Proceedings of 'ISociety 2012' at GKU, Talwandi Sabo Bathinda (Punjab).

[7] Ferry, B. (2008). Using of mobile phones to augment teacher learning in environmental education. In Hello! Where are you in landscape educational technology? Proceedings ascilite Melbourne 2008.

http://www.ascilite.org.au/conferences/melbourne08/procs/fer ry

[8] Guy, R. (2009).The Evolution of Mobile Teaching and Learning. California, Informing Science Press. p. 2.

[9] Hashemi, M., and Abbasi, M. (2013). The impact/s of Using Mobile Phone on English Language Vocabulary Retention. International Research Journal of Applied and Basic Sciences, 4 (3), 541-547.

[10] Huang, Y-M., and Hwang W. (2010). Innovations in designing mobile learning applications.www.ifets.info/download_pdf? j_id=48\&a_id=1056 (Accessed on 28 October 2).Educational Technologies and societies, Vol. 13. No. 3 (2008). pp. 1-2.

[11] Jafar, Fatima. (2008). The Use of English in Internet Communication by Jordanian Students, Al-Basaer, A Refereed Scientific, Vol.12, (2). Amman Arab University for Graduate Studies.

[12] Kafyulilo, A. (2012).Access, use and perceptions of teachers and students towards mobile phones as a tool for teaching and learning in Tanzania. Educational and information technologies journal.

[13] Kukulska-Hulme, A., and Traxler, J. (2005). Mobile learning: $A$ handbook for ducators and trainers. London: Routledge.

[14] Lave, J., and Wenger, E. (1991). Situated learning: Legitimate peripheral participation. Cambridge: Cambridge University Press.

[15] Matusov. E, Ueffing. N, and Ney. H. (2006). Computing Consensus Translation from Multiple Machine Translation Systems Using Enhanced Hypotheses Alignment. In11th Conference of the European Chapter of the Association for Computational Linguistics (EACL), pages 33-40, Trento, Italy.

[16] Reinders, H., and Lewis. M. (2009). Podquests: Language games on the go. In Language games: Innovative activities for teaching English, Vol. TESOL. ed. M. Andrade, 76-85. Alexandria.

[17] Roto, V., and Kaikkonen, A. (2003). Perception of narrow web pages on a mobile phone. In: Proceedings of the 19th International Symposium on Human Factors in Telecommunication (HFT 2003). Berlin, Germany. 1-4 December 2003, pp 205-212.

[18] Sim. C, Byrne. W, Gales. M, Sahbi. H, and Woodland. P.C. (2007): Consensus network decoding for statistical machine translation system combination. In IEEE Int. Conf. on Acoustics, Speech, and Signal Processing, Honolulu, HI, USA, April. 
[19] Thornton, P., and Houser, C. (2003). Using mobile web and video phones in English language teaching: Projects with Japanese college students. In Directions in CALL: Experience, experiments and evaluation.

[20] UNESCO, (2012). Mobile learning for teachers in Africa and the Middle East: Exploring the potentials of mobile technologies to support teachers and improve practices. unesdoc.unesco.org/images/0021/002163/216358e.pdf.
[21] Utulu, C. S, (2012).Use of mobile phones for project based learning by undergraduate students Nigerian private Universities. International Journal of Education and Development using Information Communication and Technology. Vol. 8. No. 1, pp. 1-15. 